\section{GRP-133 PHARMACEUTICAL CARE PROGRAMIME IN AN EMERGENCY DEPARTMENT}

doi:10.1136/ejhpharm-2013-000276.133

M Alvarez Payero, M Ucha Samartin, A Martín Vila, C Vázquez López, N Martínez López de Castro, G Piñeiro Corrales. Meixoeiro Hospital (CHUVI), Pharmacy, Vigo, Spain

Background Over recent decades, the pharmacist's role has evolved with the development of pharmaceutical care, defined as the active participation of the pharmacist in patient care, in collaboration with the doctor and other healthcare professionals in order to improve the patient's quality of life. Based on this, we have established a pharmaceutical care programme in an emergency department (ED).

Purpose

1. To describe more frequent pharmaceutical interventions (PIs) in an ED

2. To analyse the rate of acceptance of the PIs and which were accepted.

Materials and Methods Descriptive-prospective study, for six months, in a University Hospital. All medical prescriptions from the ED were evaluated. If any drug-related problems (DRPs) were detected, the prescriber was notified of a recommendation. The following variables were collected: sex, age, reason for the intervention: DRPs especially adaptation to the pharmaceutical guide used in the hospital (AP), medical service (emergency, medical unit, surgical unit), type of PI, type of DRP, acceptance rate (accepted, not accepted, not assessable). Data were analysed with SPSS vs. 5.

Results The pharmacist reviewed the medical orders of 987 patients. A total of 669 interventions for 320 patients ( 77 years \pm 15 , $50.3 \%$ female) were recorded. The pharmacist carried out an average of 0.7 interventions/patient throughout the study period. PIs/unit: $59 \%$ emergency, $28 \%$ medical unit, 13\% surgical unit. The reasons for interventions were: DRP (60\%) or AP (40\%) detected. Types of DRP: indication $32.6 \%$, efficacy $26.6 \%$ and safety $40.8 \%$. More frequent PIs: AP $40 \%$, posology change $26 \%$, start treatment $13 \%$, change in form of administration $10 \%$, stop treatment $8 \%$. The overall rate of acceptance of the pharmacist's recommendations was $76.8 \%$ (8.6\% rejected and $14.6 \%$ not assessable).Rate of acceptance/ unit: emergency $85 \%$, medical unit $75 \%$, surgical unit $76 \%$.

Conclusions The most frequent PIs were adaptation to the pharmaceutical guide and dosage change.

Emergencies physicians accepted more PIs than other doctors or surgeons and medical units rejected more PIs than other units $(25 \%)$.

Interventions by a clinical pharmacist had a major impact on reducing prescribing errors in the study period, thus improving the quality and safety of care provided.

No conflict of interest.

\section{GRP-134 PHARMACEUTICAL INTERVENTION IN A BRAZILIAN HOSPITAL: ANALYSIS OF INTERVENTIONS FOCUSING ON PATIENT SAFETY}

doi:10.1136/ejhpharm-2013-000276.134

C Avelar Ferreira, H Azevedo Guimarães, B Barreto Vianna, M Guatimosim Azevedo, WI Souza, GLN ZAhreddine. Hospital Galba Velloso, Farmácia, Belo Horizonte, Brazil

Background Drug interactions (DIs) occur when one drug affects the activity of another drug when both are administered together. This is clinically relevant as it may cause drug-related adverse events, and is generally preventable. [1-3]

Purpose To analyse potential DIs in prescriptions for hospitalised patients. The drugs investigated were lithium, levothyroxine, phenytoin, risperidone, clozapine, olanzapine, quetiapine and ziprasidone.
Materials and Methods A longitudinal and descriptive study of pharmaceutical interventions (PIs) conducted in a Brazilian public hospital specialising in psychiatry with 145 beds, from 5 January to 30 September 2012. The drugs analysed were lithium, levothyroxine, phenytoin, risperidone, clozapine, olanzapine, quetiapine, and ziprasidone. The searches for DIs were done once a week and categorised according to severity (mild/moderate/severe). [4]

Results 134 DIs were analysed in 108 patients. Of the 134 DIs $59.85 \%$ were mild; $19.71 \%$ moderate and $2.92 \%$ severe risk. $1.46 \%$ of all prescriptions showed moderate to severe risk and $11.68 \%$ showed mild to moderate risk. Of the 134 DIs detected, 59 resulted in a written communication to the physician. The 59 written communications sent to physicians resulted in 25 prescriptions interventions, therefore 34 did not generate a medical intervention. The drugs most frequently involved in an interaction were: lithium (58); olanzapine (44); risperidone (19); levothyroxine (4) and clozapine (7). Of all 25 prescription interventions, 14 removed the potentially risky drug; in 4 the doctor reduced the dose and the other 7 the appearance of adverse reactions was monitored. In all prescriptions with severe and moderate/severe risk the drug with potential risk was replaced and the number of DIs reduced due to pharmaceutical interventions.

Conclusions The study demonstrated the importance of pharmaceutical evaluation of potential DIs in prescriptions and provided information for the prescribing physician to increase patient safety. In addition this study showed that potential DIs generally unnoticed by the prescribing physician were detected by pharmaceutical intervention.

\section{References}

1. Oga's, Basile AC, Ch MF. Guide Zanini-Oga interactions. São Paulo: Atheneu; 2002.

2. Rodrigues ML. Prescription medication. In: Cassiani SHB, Ueta, J. patient safety in the use of medication. 1st ed. São Paulo (SP): Mosby; 2004. p. 150

3. Peral Aguirregoitia J. et al, Prospective evaluation of interaciones between drugs en una aplicación informática redeemed by patients. Farm. Hosp., Madrid, V. 31, no. 32, pp. 93-100, 2007.

4. David S. Tatro. Drug Interaction Facts, The Authority on Drug Interactions. Pharmaboobooks, 2006.

No conflict of interest.

\section{GRP-135 PHARMACEUTICAL INTERVENTION IN OUTPATIENT SAFETY: PREVENTION OF MEDICATION ERRORS IN AN INTRAVENOUS MIXING UNIT}

doi:10.1136/ejhpharm-2013-000276.135

'S Martínez, 'A Izquierdo, 'M Merchante, 'L Sánchez-Rubio, 'A Zorzano, 'L Carrillo, ${ }^{2} \mathrm{~S}$ Berisa, 'A Alfaro, 'MF Hurtado, 'P Aibar. 'Hospital San Pedro, Hospital Pharmacy, Logroño, Spain; ${ }^{2}$ Hospital b Complejo Hospitalario de Navarra, Hospital Pharmacy, Pamplona, Spain

Background The 'Study on patient safety in primary health care' (APEAS), published in 2008 by the Spanish Health Ministry declared that $48 \%$ of adverse events (AEs) detected in these patients were due to medicines errors (MEs). The Institute for Safe Medication Practices (ISMP) promotes the development of internal systems to report medicines-related incidents in hospitals in order to achieve effective preventative measures.

Purpose To analyse total errors in an intravenous mixing unit and establish checkpoints to prevent them.

Materials and Methods Prospective observational study (AugustDecember 2011) which included outpatients who might be exposed to an error with intravenous medicines. The variables were: Wrong drug, original prescription service, prescription type (manual or printed), who detected the error and process error (prescription, validation, preparation or administration). Errors were classified according to severity category and error type based on the 